\title{
4
}

\section{What Are Companies For?}

\begin{abstract}
Management by missions (MBM) starts by asking a fundamental question: What is your company for? It seems reasonable to assume that an organization and its members should have a clear idea of why they exist. In practice, however, that is not always the case. Very often, there is great confusion and conflict of opinion on this point, even within the board of directors or executive committee. In this chapter, we explore this fundamental question first by discussing the role of profit in business (as a mean or an end). Then we propose a specific definition of purpose as the synthesis of the ends of a company. We then introduce the three dimensions of an effective purpose: Authenticity, Coherence and Integrity. Finally, we discuss the relationship between personal and corporate purpose.
\end{abstract}

Keywords Purpose $\bullet$ Profitability $\bullet$ Authenticity $\bullet$ Integrity • Personal purpose

The sponsors are: DPMC Foundation \& Chair in Management by Missions and Corporate Purpose (UIC) 
It seems reasonable to assume that an organization and its members should have a clear idea of why they exist. In practice, however, that is not always the case. Very often, there is great confusion and conflict of opinion on this point, even within the board of directors or executive committee. The basic problem, when the ends ${ }^{1}$ are not clear, is that the organization becomes beholden to the utilitarian push to maximize shareholder earnings. In fact, the singular focus on shareholder return is a standard consequence of the lack of leadership toward specific ends. For this reason, companies fall into an opportunistic cycle, one that is subject to the ups and downs of the short term.

Among other problems, such an opportunistic view precludes cooperation. As Barnard said in the 1930s: "Willingness to cooperate [...] cannot develop without an objective of cooperation. Unless there is such an objective it cannot be known or anticipated what specific efforts will be required of individuals, nor in many cases what satisfactions to them can be in prospect." 2 And without cooperation, it is exceedingly difficult to get the most out of the organization's talent.

David Packard, co-founder of Hewlett-Packard, is a good example of how important it is to have a clear "why." In 1960, 23 years after the company got started, Packard began his speech at the opening of a management development program with these words:

I want to discuss why a company exists in the first place. In other words, why are we here? I think many people assume, wrongly, that a company exists simply to make money. While this is an important result of a company's existence, we have to go deeper and find the real reasons for our being. [...]

You can look around and still see people who are interested in money and nothing else, but the underlying drives come largely from a desire to do something else- to make a product-to give a service- generally to do something which is of value. So, with that in mind, let us discuss why the Hewlett-Packard Company exists. ${ }^{3}$

\footnotetext{
${ }^{1}$ We use here the term "ends" (something toward which one strives) in plural assuming that companies may exist for different reasons and not necessary for a single or ultimate end.

${ }^{2}$ Chester I. Barnard, The Functions of the Executive, op. cit., p. 86.

${ }^{3}$ From a speech given by David Packard on March 8, 1960.
} 
Like Hewlett-Packard, most companies that have made a serious effort to define their missions have started by asking themselves why they exist in the first place. Understanding this is no simple task, especially if the company is owned or controlled by more than one person.

\section{Profit: Means or End?}

The first problem we encounter when we try to define a company's ends is understanding where profit fits into the equation. In management literature, and also through the various interviews and conversations with practicing managers, we have been able to identify three perspectives surrounding the idea of profit.

The first sees profit maximization as the company's sole purpose. Ever since Adam Smith, there have been those who declare that a company must confine itself exclusively to making a profit. ${ }^{4}$ Anything else a company does, they say, can only be understood as a means of making said profit. The best-known advocate of this view is Milton Friedman, who in the early 1960s stated:

There is one and only one social responsibility of business: to use its resources and engage in activities designed to increase its profits so long as it stays within the rules of the game, which is to say, engages in open and free competition without deception or fraud. ${ }^{5}$

This concept has been present throughout the business world for decades, promoted especially by capital markets that see companies as assets that are bought and sold. ${ }^{6}$ The issue is still discussed and debated today in political, academic and business circles.

\footnotetext{
${ }^{4}$ H.T. Koplin, “The Profit Maximization Assumption," Oxford Economic Papers, vol. 15, no. 2, 1963, pp. $130-139$.

${ }^{5}$ M. Friedman, Capitalism and Freedom, University of Chicago Press, 1962.

${ }^{6}$ Jaap W. Winter, "Dehumanisation of the Large Corporation," working paper, doc. cit. Available at: https://ssrn.com/abstract=3517492 and https://doi.org/10.2139/ssrn.3517492. [Referenced: $11 / 9 / 2020]$
} 
The second viewpoint argues that profit is only one of the many ends of a company. This line of thinking contends that companies should contribute beyond profit: in the form of service to individuals, groups or society as a whole. In all it does, a company satisfies one or more needs of its various stakeholders: customers, employees, shareholders, suppliers and members of the community in which it operates. Some contributions may seem more noble or enriching than others. However, it is not our intent in this book to make a moral judgment as to whether certain activities are better than others. The point we wish to make is that, for many companies, the contribution they make to their various stakeholders is an end in itself, on a par with making a profit. In fact, that is the interpretation we have found repeated most often in corporate mission statements. $^{7}$

Lastly, the third perspective sees profit not as an end in itself, but as a means to other ends. "Profit is a necessary condition for existence and a means to more important ends, but for many visionary companies it is not an end in itself. Profit is as oxygen, food, water or blood are to the body; they are not the most fundamental things in life, but without them there can be no life." 8

How an enterprise thinks of profit is not a theoretical exercise; for it has a direct impact on the priorities and decisions made and it can affect the entire business. Take, for example, a company that declares profit to be its sole purpose. It will likely view suppliers, employees and customers as a means to achieve it instead of viewing them as collaborators toward a shared outcome. What type of company will employees, suppliers and customers prefer? We can even ask ourselves: What type of company would our shareholders prefer? Because seeing profit as a means instead of an end can ultimately lead to higher profitability. This attitude is exemplified by the company Hallmark: "We believe that financial results are indispensable, not as an end in themselves, but as a means to fulfill our mission” (Hallmark Cards Inc., Beliefs \& Values). ${ }^{\text {? }}$

\footnotetext{
${ }^{7}$ See, for example, B.R. Bartkus and M. Glassman, "Do Firms Practice What They Preach?" art. cit., pp. 207-216.

${ }^{8}$ J.C. Collins and J.I. Porras, Build to Last, Century, 1996, p. 55.

${ }^{9}$ P. Murphy, Eighty Exemplary Ethics Statements, University of Notre Dame Press, Notre Dame, IN, 1998.
} 


\section{The Danger of Simplification}

Certainly, profit may be an end for many companies. But is it the only one? The answer must be given by the managers, because the ends are decided by those in command of the ship. A single end, such as profit, simplifies decision-making. Reality becomes linear, one-dimensional: you go forward or backward, you win or you lose. However, not all realities are linear. One simple example: we live in a three-dimensional reality (not counting the time dimension). Reducing our reality to two dimensions, like on screens, is fine for simulations or video games, but it does not quite capture the richness of our real experience.

Our business reality has changed remarkably already this century. In the twentieth century, when it was enough to have a "workforce" (the cheaper the better), customers were limited to a geographical area and reputation was not a key issue, we could simplify reality by just focusing on economic efficiency. But in today's world, many of these variables have become critical and cannot be safely ignored. Oversimplifying the company's ends may become an outright attack on the beliefs of many of the people who work for it, undermining their motivation and commitment. ${ }^{10}$

When profit is the sole end, everything else becomes a means. Imagine, for example, the case of a private hospital. Doctors would challenge us if we suggested that the reason their hospital exists is to "make money." If we are talking about a private hospital, the inaccuracy of our assumption is plain to see. In other cases, however, where the business activity does not have such a clear social dimension, the error may not be so obvious.

A singular focus on profit is not the only type of oversimplification. Statements such as "we exist to serve our customers" or "the company's true purpose is its people" can lead to the same mistake. Customers or people may be a company's end, but can they be the only one? It is important to think ahead and be careful when making such claims, as such "catchphrases" often lead to inconsistencies and do nothing more than create confusion and skepticism.

\footnotetext{
${ }^{10}$ B.L. Parmar, A. Keevil and A.C. Wicks, "People and Profits: The Impact of Corporate Objectives on Employees' Need Satisfaction at Work," Journal of Business Ethics, vol. 154, no. 1, 2019, p. 13.
} 
To avoid oversimplification, we need to overcome our natural inclination to see the ends of the company as a dilemma: either one thing or the other. The key insight is precisely that this is not an either/or choice, but a quest for balance and complementarity. Understanding that, we overcome the tyranny of "A or B" and start to think in terms of "A and B."11 We then stop talking about a single end and talk instead about several ends: profit, people, customers, shareholders... Henry Morgan, the author of Ben \& Jerry's mission statement (a company known worldwide for its sense of mission), said in an interview: "Most missions that focus on just one aspect are unhelpful. That is why, for Ben \& Jerry's, I wrote three missions: the product mission, the economic mission and the social mission." 12

\section{Balance and Complementarity}

Accepting that the company has multiple ends leads to a new problem: how to find the right balance and complementarity between different ends. In principle, one might assume that all a company's ends should be given equal importance. But the answer is usually not that simple. Finding the right balance in each case is an important part of defining the company's purpose.

One of the best-known developments that defend this perspective is Michael Porter's theory of creating shared value, whereby the company shares a duality of economic and social ends. ${ }^{13}$ This philosophy, which proposes a way to "reinvent capitalism," has been embraced by numerous corporations such as Google, Intel, IBM, General Electric, Nestlé, CocaCola, Johnson \& Johnson and Unilever. According to this philosophy, companies must seek initiatives that simultaneously create economic value and progress in the communities where they operate. This approach

\footnotetext{
${ }^{11}$ J.C. Collins and J.I. Porras, Build to Last, Century, 1996, p. 55.

${ }^{12}$ P. Jones and L. Kahaner, Say It and Live It: 50 Corporate Mission Statements That Hit the Mark, Currency Doubleday, 1995.

${ }^{13}$ M.E. Porter and M.R. Kramer, "The Big Idea: Creating Shared Value. How to Reinvent Capitalism-And Unleash a Wave of Innovation and Growth," Harvard Business Review, 89, no. 1-2, 2011.
} 
is also related to the Sustainable Development Goals (SDG), through which companies try to solve social problems related to water, environmental impact, education, health and so on. ${ }^{14}$

The quest for balance also requires managing the tensions generated by the compatibility of diverse ends. This is the case of a water supply company whose objective is to profitably sell water, while at the same time encouraging reduced consumption. These two objectives are in conflict, but they are not incompatible. Battilana's research on how to manage conflicts in dual-purpose settings shows that the key is to build a commitment to creating both economic and social values into their core activities. ${ }^{15}$ Is it easy? Not at all. Is it impossible? Definitely not. There are plenty of successful companies to prove it.

We may wonder how these companies are able to combine such diverse ends. There is no simple answer, no one way of doing it. Instead, Battilana offers some recommendations, such as prioritizing and monitoring objectives in the two dimensions, hiring employees who are committed to both goals and practicing leadership that combines economic and social values.

Ultimately, every company must find its own way of combining the different ends that come into play when decisions are made. It would be much easier if the company had just one decision criterion: profit, for example. But such simplicity, besides impoverishing the decision process, would also diminish the company's purpose and, with it, people's commitment to the enterprise. This approach can be seen in the transition of many companies that have shifted from offering a certain product or service to embracing a broader purpose (see examples in Table 4.1).

Table 4.1 From product/service to purpose

\begin{tabular}{lll}
\hline Company & Traditional positioning & New positioning \\
\hline Nestlé & Food and beverage & Nutrition \\
Nike & Footwear and sportswear & Well-being \\
IBM & Computers & Information \\
\hline
\end{tabular}

\footnotetext{
${ }^{14}$ See: https://www.un.org/sustainabledevelopment/es/. [Referenced: 11/9/2020]

${ }^{15}$ J. Battilana, A.C. Pache, M. Sengul and M. Kimsey, "The Dual-Purpose Playbook," Harvard Business Review, March-April 2019.
} 
The theory of creating shared value between an economic goal and a social goal is not the only way to enrich the one-dimensional view of profit maximization. As we saw before, Ben \& Jerry's developed a purpose with, in their case, three distinct supporting missions: product, economic and social.

\section{Organizational Purpose}

As we have seen, one of management's toughest challenges is finding the right balance and complementarity among the company's various ends. From now on, we shall use the word purpose to refer to a company's multiple ends. Specifically, we define purpose as the synthesis of the ends of a company, its ultimate reason for existence. We do so in order to emphasize the fact that an organization's ends are not separate and disjointed but a cohesive whole. An organization's purpose, therefore, is not the sum of various unrelated ends, but a rich and complex whole encompassing a variety of ends which support and reinforce one another in many different ways.

The formulation of the purpose is usually done through short phrases or concepts that reflect the essence of the company's goals. To "relieve pain," "boost well-being," "give meaning to work," "improve life," "inspire happiness" and so on. Purpose recognizes the interdependence of business and society. ${ }^{16}$ For example, Disney's purpose is to "use our imaginations to bring happiness to millions"; 3 M's purpose is "advancing every company, enhancing every home, improving every life"; and Google's is to "organize the world's information and make it universally accessible and useful."

In recent years, several studies have shown the positive effects of creating a purpose in different settings, both internal and external. These are some of the notable impacts: ${ }^{17}$

\footnotetext{
${ }^{16}$ E. Hollensbe, C. Wookey, L. Hickey, G. George and C.V. Nichols, “Organizations with Purpose," art. cit., pp. 1227-1234.

${ }^{17}$ Summary prepared by A. Lleó, “The Power of Purpose,” unpublished paper, 2020.
} 
- Commitment to the company. Purpose is positively correlated with engagement and job satisfaction (Allan et al., 2019). ${ }^{18}$

- Attraction, motivation and retention of young talent. "Sixty percent of millennials (35\% of the workforce) believes that a company's main objective should be improving society rather than generating profits" (Deloitte, 2018). ${ }^{19}$

- Change and innovation. "Eighty-four percent of managers said businesses with shared purpose would be more successful in transformation efforts" (HBR, 2015). ${ }^{20}$

- Flexibility, agility and resilience in VUCA environments. ${ }^{21} 73 \%$ of business leaders said that, "having a well-integrated purpose will help their company navigate disruption" (EY-Beacon Institute, 2017). ${ }^{22}$

- Profitability. "Organizations with a strong sense of purpose are more than twice as likely to have above-average performance for shareholders" (BCG, 2020). ${ }^{23}$

- Relations with customers and other stakeholders. "Organizations with a purpose build greater customerloyalty by 52\%" (EY-Beacon Institute, 2017). ${ }^{24}$

- Reputation and legitimacy. "Purpose drives 13\% of a company's overall reputation. 88 percent of companies with a strong reputation have strong purpose scores" (Porter Novelli/Cone Purpose Premium Index, 2018). ${ }^{25}$

Considering this, we can conclude that purpose is not just another tool in the organization, like the communication plan; it is a reality that affects the very heart of the company. As Barnard said, purpose is the objective

\footnotetext{
${ }^{18}$ B.A. Allan, C. Batz-Barbarich, H.M. Sterling and L. Tay, "Outcomes of Meaningful Work: A Meta-Analysis," Journal of Management Studies, vol. 56, no. 3, 2019, pp. 500-528.

${ }^{19} \mathrm{See}$ https://www2.deloitte.com/global/en/pages/about-deloitte/articles/millennialsurvey.html. [Referenced: 11/9/2020]

${ }^{20}$ See https://hbr.org/resources/pdfs/comm/ey/19392HBRReportEY.pdf. [Referenced: 11/9/2020]

${ }^{21}$ VUCA: volatility, uncertainty, complexity and ambiguity.

${ }^{22}$ See https://www.ey.com/Publication/vwLUAssets/ey-the-state-of-the-debate-on-purpose-inbusiness/\$FILE/ey-the-state-of-the-debate-on-purpose-in-business.pdf. [Referenced: 11/9/2020] ${ }^{23} \mathrm{See}$ https://www.bcg.com/featured-insights/how-to/purpose-driven-business. [Referenced: $11 / 9 / 2020]$

${ }^{24} \mathrm{See} \quad \mathrm{https} / /$ assets.ey.com/content/dam/ey-sites/ey-com/en_gl/topics/purpose/ey-the-state-ofthe-debate-on-purpose-in-business.pdf. [Referenced: 11/9/2020]

${ }^{25}$ See https://www.conecomm.com/research-blog/purpose-premium. [Referenced: 11/9/2020]
} 
of cooperation that makes the organization possible. Some authors even argue that a company without a purpose is not a company: at most, we would be talking simply about a business. ${ }^{26}$ And not every employee in a company is truly a member of that organization (even if they formally belong to it through an employment relationship). For a person to be truly - not just formally - a member of an organization, it takes more than just a contract. An employee is only a member if they share a common purpose with the rest of the organization, regardless of the personal motives that led them to join the company.

\section{Purpose and Sense of Purpose}

The results that we summarized in the previous section may surprise those who believe that purpose is just a fad or a marketing gimmick. In a way, they are right, especially in some cases. In most of the companies that we have studied, particularly those we labeled as competent, we find that purpose is an element of high added value. However, we have also found that, for other companies, purpose has been nothing more than window dressing: a time of reflection, followed by somewhat vigorous communication that produces some hope for change, but has not yet fully taken hold. This reality leads us to conclude that there is a big difference between defining a purpose and creating a true sense of purpose in the company.

So, how do you build a true sense of purpose in your company? It's not easy, because a sense of purpose in the company only exists when people embrace the purpose as their own and act accordingly. The company purpose is not just for top management. Logically, managers should be the first to have a shared purpose and exhibit exemplary behavior. But, at the end of the day, the strength of a company's purpose will depend on how well it is implemented across the organization, regardless of people's managerial level, role or tenure with the company.

There are three essential conditions for successfully implementing purpose: people must know the purpose, accept it and practice it. With that,

\footnotetext{
${ }^{26}$ N. Chinchilla and J.A. Pérez López, "Business or Enterprise? Different Approaches for the Management of People in Organizations," IESE, technical note FHN-216, 1990.
} 


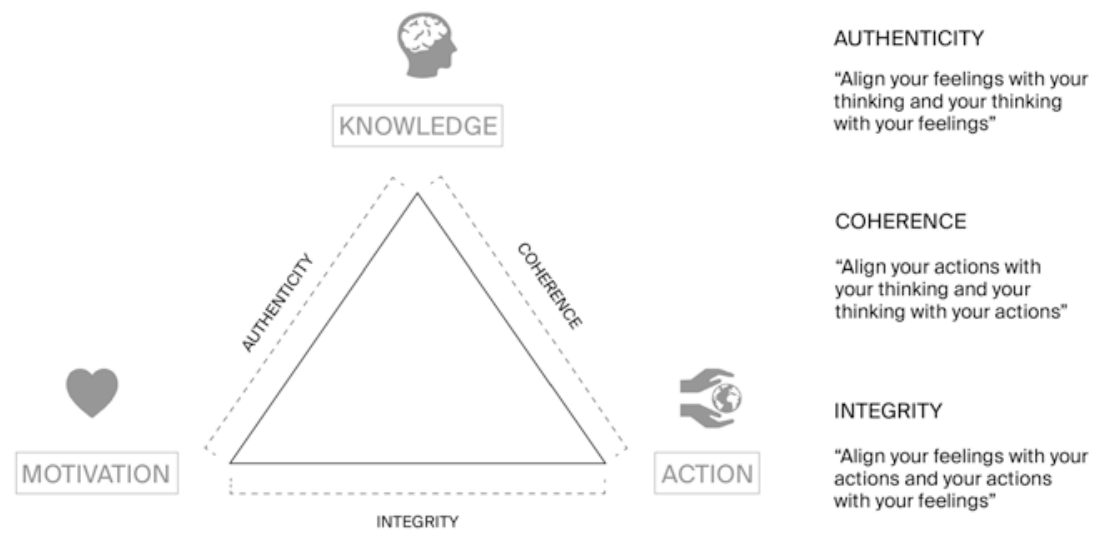

Fig. 4.1 Dimensions of purpose

we can define three dimensions of purpose: ${ }^{27}$ knowledge (your formal statement); motivation (the internalization of purpose as something felt and wanted by people); and action (the practical fulfillment of purpose in daily operations). The interaction between these dimensions creates the conditions that differentiate the mere purpose statement from the true sense of purpose: coherence, authenticity and integrity. ${ }^{28}$

These three characteristics multiply and reinforce one another; so, if one of them falters, the sense of purpose diminishes. This is supported by the recent studies of Lleó et al. on a sample of companies that practice management by missions. ${ }^{29}$ These ideas are illustrated in Fig. 4.1.

\section{Coherence}

Purpose is far more than a catchphrase or idea. The coherence of the purpose is related to action, to the organization's daily operations, and is a vital condition for generating a sense of purpose. It's essentially to "align

\footnotetext{
${ }^{27}$ C. Rey and M. Bastons, "Three Dimensions of Purpose: Knowledge, Motivation, and Action, in Purpose-Driven Organizations, op. cit., pp. 29-41.

${ }^{28}$ C. Rey and M. Bastons, "Three Dimensions of Effective Mission Implementation," Long Range Planning, vol. 51, no. 4, 2018. pp. 580-585.

${ }^{29}$ Á. Lleó, M. Bastons, C. Rey and F. Ruiz-Pérez, "Purpose Implementation: Conceptualization and Measurement," working paper, June 2020. Available at: https://papers.ssrn.com/sol3/papers. cfm?abstract_id=3630416. [Referenced: 11/9/2020]
} 
your actions with your thinking and your thinking with your actions."30 It's about being aware of the reason why you do things and having that guide your actions and inspire your daily endeavors. Or in the broader sense, raise awareness and understanding about the purpose, then keep the promise and stay on track. ${ }^{31}$ The coherence of the purpose comes from both the internal structure of the statement and the different policies created to make it tangible. Ambiguous purpose statements undermine the coherence of the purpose and often lead to inconsistent decisions across the organization. Likewise, policies misaligned with the purpose can bring about operational incongruencies. For example, an incentive system that only considers financial results may motivate employees in ways that are counter to the organization's communicated purpose. This incoherence is one of the biggest sources of distrust and kills the sense of purpose in the organization.

\section{Authenticity}

For purpose to be authentic, it has to come from within and reflect the feelings and motivations of the people who work for the company. It's to "align your feelings with your thinking and your thinking with your feelings.”

The authenticity of purpose lies within people and their personal commitment. Given that, a company's purpose must resonate with the personal purpose of the people who work there. Alex Gorsky, CEO of Johnson \& Johnson, explains how the company seeks authenticity in its purpose: "We're focusing a lot of our attention on helping our employees find and activate their own purpose and connect it with our purpose. We've seen that cultivating and developing a deep sense of purpose leads to employees who are more engaged, both personally and professionally. And the data show that focusing on purpose actually leads to many improved outcomes_-physically, mentally and emotionally." 32

\footnotetext{
${ }^{30}$ Our thanks to John Almandoz for his suggestions in developing the definitions of coherence, authenticity and integrity.

${ }^{31}$ N. Craig, Leading from Purpose: Clarity and the Confidence to Act When It Matters Most, Nicholas Brealey Publishing, London, 2018.

${ }^{32}$ See https://www.jnj.com/latest-news/johnson-johnson-ceo-alex-gorsky-reflects-on-the-powerof-the-companys-credo. [Referenced: 11/9/2020]
} 
Purpose cannot be invented at the top of the company and then imposed downward. Authenticity is not born out of communication campaigns or marketing activities. Purpose must be discovered within the organization, because it is already alive and well among its members. ${ }^{33}$ Authentic leadership ${ }^{34}$ is not about the boss imposing their personal vision, or even linked to hierarchical power at all. The new leadership is a shared leadership, since the purpose is also shared, and everyone-regardless of their position in the hierarchy-is committed to fulfilling it. ${ }^{35}$

\section{Integrity}

When purpose is integrated in both the daily operations and organizational culture, it becomes a shared motivation. Integrity is to "Align your feelings with your actions and your actions with your feelings."

Purpose is felt and carried out throughout the organization as something natural. ${ }^{36}$ Integrating purpose into the culture and values of its members is a way to create unity, both internally and externally. The purpose becomes a habit, a spontaneous way of life within the company and of interacting with stakeholders. This habit, which we call integrity, is the foundation of trust between stakeholders, and it builds reputation.

As with any habit, the relationship between motivation and action is bidirectional. Learning occurs through action. And not only operational learning (how to do something you didn't previously know how to do), but most importantly affective learning (how to value, thanks to experience, what was not previously valued). ${ }^{37}$ For example, many companies offer volunteer programs to raise employee awareness about particular needs in the community where they live (such as orphaned children, the elderly, etc.).

\footnotetext{
${ }^{33}$ R.E. Quinn and A.V. Thakor, “Creating a Purpose-Driven Organization,” art. cit., pp. 78-85. ${ }^{34}$ B. George, True North: Discover Your Authentic Leadership, Jossey-Bass, San Francisco, 2007.

${ }^{35}$ P. Cardona, C. Rey and N. Craig, "Purpose-Driven Leadership," in Purpose-Driven Organizations, op. cit., pp. 57-71.

${ }^{36}$ F. Marimón, M. Mas-Machuca and C. Rey, "Assessing the Internalization of the Mission," Industrial Management \& Data Systems, vol. 116, no. 1, 2016, pp. 170-187.

${ }^{37}$ Pablo Cardona and Pilar García-Lombardía, Cómo desarrollar las competencias de liderazgo, EUNSA, Barrañáin, Navarra, 2005.
} 
In summary, developing a sense of purpose in the company is an undertaking that requires much more than a statement on the website or a few end-of-year sermons. Many companies would like to reap the benefits of an organization with a sense of purpose. But they remain anchored in management methods that focus on the coordination of objectives and activities and forget to develop a true sense of purpose among their members. Basically, they go to great lengths to tell each person what they have to do and even how to do it, yet rarely provide the means to help employees understand the purpose of their work.

\section{Personal Purpose}

As one might imagine, personal purpose — an individual's reason for existence in this world ${ }^{38}$ - is a bit different from the organizational purpose that we are referring to here. Now, the two concepts are closely related: as we saw in the previous section, personal purpose is a key element in developing the organization's purpose. ${ }^{39}$ We could say that the company purpose is fulfilled through the purpose of each of its members. This scenario was brilliantly captured by Lorenzo Servitje, president of the Mexican multinational Bimbo, the world's largest baking company, with over 100,000 employees worldwide. This is how he explained to his collaborators the relationship between individual and company purpose: "The company has a soul made by the souls of each of its workers."

While this book is not about personal purpose_-at least not directlywe would like to offer three considerations about the differences and relationships between personal and corporate purpose:

1. Corporate purpose is not personal purpose. Although for some founders or managers the purpose in their life may be closely aligned with that of the company they run, these are two distinct concepts. In fact, one could easily think that someone's personal purpose surely will consist of different aspects than their company's purpose. In this regard, each

\footnotetext{
${ }^{38}$ A. Hurst, The Purpose Economy: How Your Desire for Impact, Personal Growth and Community is Changing the World, Elevate Publishing, Boise, ID, 2016.

${ }^{39}$ C. Rey, J.S. Velasco and J. Almandoz, "The New Logic of Purpose Within the Organization," in Purpose-Driven Organizations, op. cit., pp. 3-15.
} 
person is unique and, therefore, has a particular purpose, a specific reason for being in the world that encompasses various facets of their life: family, professional, social and so on.

2. Corporate purpose does not override personal purpose. Just because someone shares the corporate purpose doesn't mean they can't fulfill their own personal purpose at work. Managers and employees may occasionally lose sight of that and act as if there truly is no purpose in life beyond the corporate purpose. This is something that companies need to understand clearly since, especially with millennials and younger generations entering the workplace, combining work with personal purpose is more and more the expectation. People want to fulfill their personal purpose at work in order to live their professional and personal life more fully. ${ }^{40}$ Companies must understand this reality and create the appropriate contexts for people to reflect their own purpose through their work.

3. Corporate and personal purposes can be complementary. Sharing the corporate purpose is an invitation for each member of the organization to make it part of their purpose in life. It is a two-way relationship in which the company and individual mutually appreciate one another's purposes. ${ }^{41}$ In other words, the two do not have to be mutually exclusive. ${ }^{42}$ The purpose of an organization can complement and create synergy with an individual's purpose by giving them a greater sense of contribution and fulfillment through their daily work. ${ }^{43}$ This connection happens to be source of the authenticity that we just mentioned. In fact, increasingly more companies from diverse sectors-such as Unilever, Medtronic and Telefónica—are developing programs for their employees to discover and explore their personal purpose. ${ }^{44}$

\footnotetext{
${ }^{40}$ G.B. Grant, "Exploring the Possibility of Peak Individualism, Humanity's Existential Crisis, and an Emerging Age of Purpose," Frontiers in Psychology, vol. 8, 2017, p. 1478.

${ }^{41}$ C. Rey and I. Malbašić, "Harmonization of Personal and Organizational Purpose," in PurposeDriven Organizations, op. cit., pp. 17-27.

${ }^{42}$ L. Ramarajan and E. Reid, "Shattering the Myth of Separate Worlds: Negotiating Nonwork Identities at Work," Academy of Management Review, vol. 38, no. 4, 2013, pp. 621-644.

${ }^{43}$ B.B. Caza, S. Moss and H. Vough, "From Synchronizing to Harmonizing: The Process of Authenticating Multiple Work Identities," Administrative Science Quarterly, vol. 63, no. 4, 2017, pp. 703-745.

${ }^{44}$ C. Rey, J.S. Velasco and J. Almandoz, “The New Logic of Purpose Within the Organization,” in Purpose-Driven Organizations, op. cit., pp. 3-15.
} 
To sum up these considerations, we could say that the personal purpose of each member of the company should not be discounted or ignored as if it had nothing to do with the company. Doing so would be regressing back a century, when employees were treated as human resources. Modern companies need to treat employees as people, all of whom have their own purpose in life. As such, they should do their best to support (or at least not impede) each person's quest to fulfill their personal purpose and help them connect their personal purpose with the corporate purpose.

When corporate and personal purposes are compatible, it becomes much easier to recruit and retain talent, and people are more likely to be engaged and identified with the organization's purpose. In the next chapter, we will delve into how one complements the other. To do this, we will focus on the for whom, that is, the impact of the purpose on people's life.

\section{"Value Life"}

Vygon Spain is the Spanish subsidiary of the French multinational Vygon, based in Écouen (north of Paris). The Vygon Group is present in 120 countries and provides medical supplies (catheters, probes, ventilation equipment) to hospitals, private clinics and emergency units. In 2014, Vygon Spain started implementing management by missions. Florent Amion, its director since 2004, tells us about his experience:

"I took over the management of Vygon Spain when I was 30. I worked really hard, with all the energy of a newcomer. Then came the crisis in 2008 and, later on, a personal crisis. Nearing the age of 40, everything seemed scary to me. I had spent 'my whole life' at the same company. All of these unfounded doubts kept tormenting me: What would happen to me if Vygon were bought out? What would become of my career? And deeper fears, like: Is it going to be like this for the rest of my career? Is there nothing more to it than buying and selling?

"I started to investigate and I found coaching, positive psychology, neuroscience... And then a friend introduced me to the book Management by Missions. I read it three times in a row; it was a real eye-opener.

"In traditional, objectives-based organizations, each department defends its territory and its logic (the finance department defends its profitability objectives, sales defends its volume objectives, etc.), which creates silos and conflicts. Management by missions creates unity, alignment and integration of the teams because it is based on the principle of transcendent motivation, in which each individual asks: What am I doing as a human being in my company to change the world? The purpose of the Vygon Group-whose 


\section{(continued)}

brand motto is 'Value life' - meshed nicely with this idea of what we wanted to contribute to the world. But we had to convey this idea to all of our employees. Build real unity through specific actions.

"So we started with the company purpose to make it as accessible as possible to people. We began in January 2014. We made the decision knowing there was no going back. I thought it would take us six months, seeing how much our culture intersected with this management method. But it ended up taking us three and a half years. We've invested a lot. We did individual training, group sessions, developed new management tools, coaching, meditation... The hardest part was the leadership deployment. We didn't realize what a demanding change that requires. For managers in particular, moving from a traditional leadership style to a transcendental leadership style was not easy. You don't realize that you have to add projects and tasks to your to-do list that don't involve the P\&L.

"Implementing our purpose gave way to countless initiatives, such as creating an optimistic building, where employees co-created the entire office décor, over a hundred work-life balance measures, and many leadership development initiatives. We also decided in 2015 to create some awards to improve the management of hospitals, which we call optimistic hospital, to honor the heroes who take care of us when we need it most. This is now the sixth edition and the fourth time that the Queen of Spain is president of the Committee of Honor.

"Professionally, I have completely transformed my role. As a leadercoach, I help people find solutions. I used to be the one who knew it all; now I don't know anything," he says with a smile. "I trust that others will get to the heart of things... Sometimes it's strange. If you don't have great confidence in yourself, in others and in your purpose, it's going to be tough. What interests me is not power; it's having authority. What's more interesting to me is taking a step back, getting away from the action to pick your head up and look further ahead. It's very liberating.

"Being at the service of others is the loveliest gift you can give yourself. It gives me great inner peace. And when you meet people who are having the same experience, you tell yourself that anything's possible, and you can dream of things you would never have even thought of before. During these years, I have achieved three key transformations. First, constantly learning to transform myself personally; second, to transform my organization in such a way that it inspires other companies; and third, to transform the organizational culture in hospitals around the world to reduce patient suffering. Now I'm at a good point in my life where I feel that my personal purpose is aligned $100 \%$ with my work.

"Pursuing this purpose gives me a lot of satisfaction. Much more than I can get from improving Vygon's annual profit results... which, incidentally, keeps happening year after year as a 'magical' consequence of this process. To some 


\section{(continued)}

degree, sales figures and everything else are just an excuse to keep working to make things around you different. In an industry that has seen minor ups and downs since 2014, our organization has had an average annual growth of $5 \%$, and I am convinced that purpose has had a lot to do with this.

"We've also seen this during the COVID-19 pandemic. In our organization, we've launched many initiatives to support health workers, and, through social media, we've been able to stay in contact with our clients 'as if nothing had happened.' We've also maintained unity among our people, getting them quickly adapted to the online world. Thanks to the work-life balance measures that we'd implemented a few years back, confinement wasn't a major shock for us. Although we definitely miss physical contact between colleagues, because virtual just isn't the same. To help offset all the isolation, we organize dinners or lunches by department, respecting the regulations in force at all times. We use the auditorium mode in Microsoft Teams so we can all see each other at the same time. But that's just further proof that we need each other."

Open Access This chapter is licensed under the terms of the Creative Commons Attribution 4.0 International License (http://creativecommons.org/licenses/ by/4.0/), which permits use, sharing, adaptation, distribution and reproduction in any medium or format, as long as you give appropriate credit to the original author(s) and the source, provide a link to the Creative Commons licence and indicate if changes were made.

The images or other third party material in this chapter are included in the chapter's Creative Commons licence, unless indicated otherwise in a credit line to the material. If material is not included in the chapter's Creative Commons licence and your intended use is not permitted by statutory regulation or exceeds the permitted use, you will need to obtain permission directly from the copyright holder.
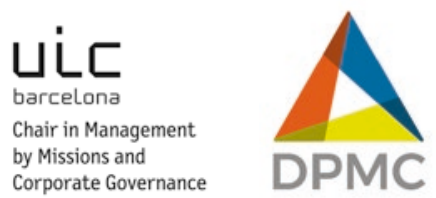